\title{
EDITORIAL
}

\section{TO DRUG OR NOT TO DRUG: THE GERIATRICIAN DILEMMA OF POLYPHARMACY}

\begin{abstract}
I. APRAHAMIAN ${ }^{1,2}$, J.E. MORLEY ${ }^{3}$
1. Group of Investigation on Multimorbidity and Mental Health in Aging (GIMMA), Geriatrics division, Jundiai Medical School, Jundiai, Brazil; 2. University of Groningen, University Medical Center Groningen, Department of Psychiatry, Groningen, The Netherlands; 3. Division of Geriatric Medicine, Saint Louis University School of Medicine, St. Louis, Missouri, USA. Corresponding author: John E. Morley, MB, BCh, Division of Geriatric Medicine, Saint Louis University, SLUCare Academic Pavilion, Section 2500, 1008 S. Spring Ave., 2nd Floor, St. Louis, MO 63110, Email: john.morley@health.slu.edu, Twitter: @drjohnmorley
\end{abstract}

Key words: Polypharmacy, drug interactions.

"The first duties of the physician is to educate the masses not to take medicine." "imperative drugging - the ordering of medicine in any and every malady is no longer regarded as the chief function of the doctor." $\sim$ William Osler

Older adults often present with multimorbidity. More than half of those over the age of 65 have multiple chronic diseases, and this percentage goes up to $80 \%$ in persons aged 80 and more $(1,2)$. In Western medicine, most treatment strategies for chronic diseases rely on drugs. Reasons for treatment, beyond those related to specific consequences of single diseases, include several adverse outcomes of multimorbidity such as functional impairment, poor quality of life, and high health care utilization and its costs (2-4). Randomized controlled trials aimed to test the effectiveness of non-pharmacological approaches, multidimensional interventions or a patientcentered intervention are lacking, resulting in pharmacological treatment with multiple drugs being the most common strategy to treat older adults with multimorbidity (5-7). A recent nationally representative sample of 2206 community-dwelling older adults aged 62 through 85 years was conducted in the United States regarding the use of medication between 2005 and 2006, and again in 2010-2011 (8). Five or more prescribed drugs were used by $36 \%$ of participants. Moreover, in another report of Medicare beneficiaries admitted to a nursing facility after hospital discharge, an average of 14 medications were used by patients (9). At least $30 \%$ of these drugs showed side effects hazardous to 5 geriatric syndromes evaluated in this study. Polypharmacy refers to multiple medication use and is most commonly defined quantitatively as the chronic use of 5 or more prescribed drugs (10). Polypharmacy increases the adverse reactions burden associated with multimorbidity independently resulting in negative outcomes, such as frailty, falls, cognitive impairment, functional disability, weight loss, hospitalization and mortality (11-19).

The association between multimorbidity and polypharmacy among older adults appears to be unbalanced and often fails to take into account the physiological changes of aging that modulate the efficacy of medications (Figure 1). For example,

$20 \%$ of Medicare patients in the USA present 5 or more chronic illnesses while $50 \%$ use 5 or more medications (20). The greater the use of prescribed and unprescribed (over-the-counter and herbal drugs), the greater the risk of an adverse drug event. This is particularly relevant for older individuals who intrinsically present pharmacokinetic and pharmacodynamic alterations of aging such as an increased body fat compartment relative to skeletal muscle composition, decreased drug clearance and hepatic metabolization, and increased plasma concentration. Notwithstanding, polypharmacy increases the risk of inappropriate prescribing, iatrogenic "prescribing cascades", drug-drug and drug-disease interactions, and exacerbation of adverse effects of individual medications such as antidepressants and antipsychotics (21). This later group of drugs deserves special attention due to their anticholinergic activity resulting in many adverse events such as blurred vision, newer or worsening cognitive impairment, confusion, hallucinations, pneumonia, dry mouth, constipation, urinary retention, tachycardia, and increased mortality (22). Most importantly, anticholinergic burden independently increases the risk of dementia and Alzheimer's disease (23). Three geriatric syndromes are also associated with polypharmacy, namely falls, frailty, and delirium. However, more longitudinal studies are needed. Polypharmacy was associated with increased risk for falls in adults aged 50 years and more with a 2-year follow-up (24). This risk was independent from the individual medication increased falling risks. A possible association between medication harm, polypharmacy and frailty has been suggested $(25,26)$. Polypharmacy presented high prevalence in most cross-sectional and longitudinal studies, and it was associated with incident frailty (27-31). The association between frailty and polypharmacy is not related to the number of medications involved (27) and presents more negative outcomes among those cognitively impaired or defined as cognitively frail (30, 32). Persons with polypharmacy are at a high risk of developing delirium and reducing drug burden, especially anticholinergic drugs, reduce delirium (33).

Overall, several adverse effects and consequent geriatric syndromes derived from polypharmacy may be related or interconnected. For example, a selective serotonin receptor 
inhibitor could lead to a higher anticholinergic burden, hyponatremia, orthostatic hypotension and falls. Hospital admission, excessive prescribed rest and opioids could increase anticholinergic load, sarcopenia, cognitive impairment and delirium. The ultimate consequence would be frailty. It is common to identify an important iatrogenic component in the polypharmacy cycle of events in clinical practice (26). Several key steps might mitigate the negative effects of polypharmacy (34) (Table 1). First a regular medication review is mandatory to evaluate superfluous drugs, medication effectiveness, underprescription, balancing risks and benefits of prescribed items, and establishing goals of individual drugs. It is mandatory to always reevaluate a patient's expectations regarding life expectancy, quality of life and disease course. The classical "start low and go slow" is a modern dogma when targeting polypharmacy. Most adverse events from medications are dose-related (35). Deprescribing medications is fundamental. In a large study with Medicare patients with a bone fracture, three quarter had been prescribed a high-risk medication for fracture a few months before falling, and only $7 \%$ of patients had that drug withdrawn (36). Most physicians are reluctant in withdrawing drugs. Several guidelines and instruments help in prescription decisions regarding over-prescription and inappropriate drug use in hospitalized, nursing home or outpatient setting. The most common criteria used are the 2019 updated Beers, the Screening Tool of Older Person's Prescriptions (STOPP), the STOPP/START (Screening Tool to Alert doctors to the Right Treatment), the FORTA (Fit FOR The Aged) list, and the Drug Burden Index (37-41). Any of these instruments are useful to help deprescribing decisions or drug substitutions especially in polypharmacy and when a high-risk of drug-interaction is suspected. It is recommended to stay alert and consider an adverse drug effect when a new symptom is referred to avoid an iatrogenic cycle. In modern times anytime a new drug is prescribed, the computer should check for drug-drug interactions and drugs that are not suitable for use by older persons. In more complex clinical scenarios, a pharmacist evaluation of prescribed items and non-pharmacologic treatments may present an important role. Finally, it is of utmost importance to reassure the patient's capacity to acquire and properly use a medication list, including their cognitive ability and social network (42). To deal with polypharmacy is the essence of being a geriatrician, and medication harm could be considered a geriatric syndrome that must be prevented (43). It is imperative to systematically address the dilemma of drug prescription among older adults.

To conclude, in a classical overstatement, Oliver Wendell Holmes said, "I firmly believe that if the whole material medica, as now used, could be sunk to the bottom of the sea, it would be all the better for mankind - and all the worse for the fishes." It must be recognized that most new drugs have not been tested in older persons and often produce a minimal improvement over older drugs at a large increase in price. The need to use these drugs needs to be carefully discerned by the physician and their use in a frail person with a limited lifespan be used only when there is a clear advantage.

Table 1

Proposed Strategies to Manage Polypharmacy

1. Identify the target problem being treated by the drug

2. Is the drug necessary?

3. Does the drug interact with other drugs the patient is receiving causing side effects?

4. Is the drug at the lowest necessary dose?

5. Would discontinuing therapy with a medicine help reduce symptoms?

6. Is the drug contraindicated in an older person?

7. Does the drug have side effects that are more likely to occur in older persons?

8. Is the drug the most cost-effective choice?

9. Are nonpharmacologic therapies available?

10. Is the patient noncompliant?

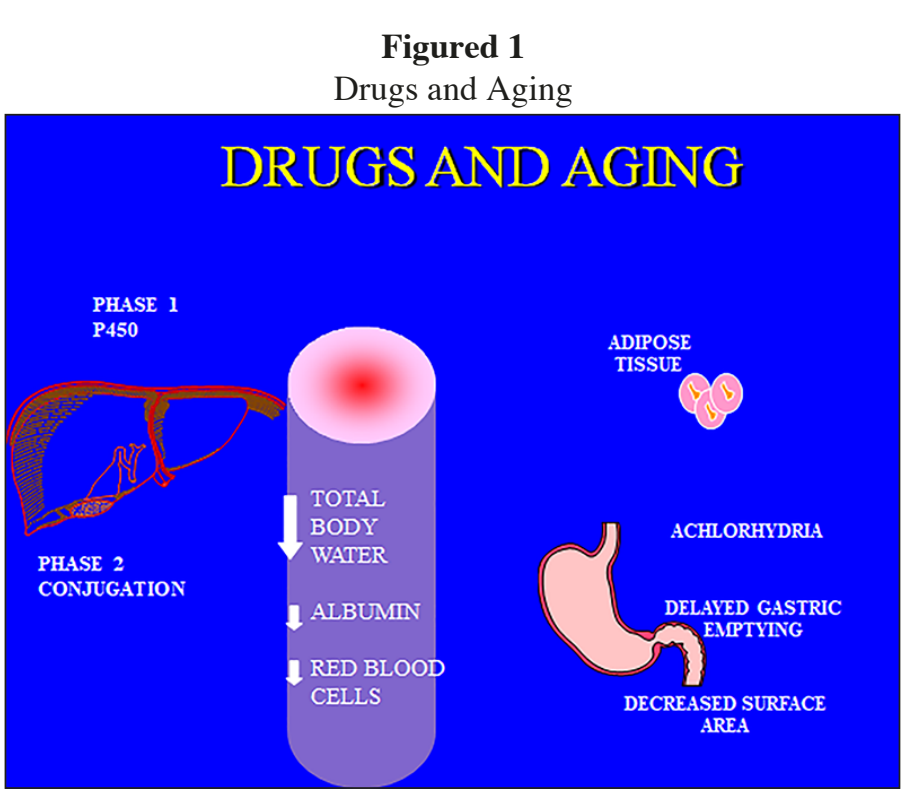

Disclosures: The authors declare there are no conflicts.

\section{References}

1. Barnett K, Mercer SW, Norbury M, et al. Epidemiology of multimorbidity and implications for health care, research, and medical education: A cross-sectional study. Lancet 2012;380:37-43.

2. Kernick D, Chew-Graham CA, O'Flynn N. Clinical assessment and management of multimorbidity: NICE Guideline. Br J Gen Pract 2017;67:235-236.

3. Marengoni A, Angleman S, Melis R, et al. Aging with multimorbidity: A systematic review of the literature. Ageing Res Rev 2011;10:430-439.

4. Nunes BP, Flores TR, Mielke GI, et al. Multimorbidity and mortality in older adults: A systematic review and meta-analysis. Archives of Gerontology and Geriatrics 2016;67:130-138.

5. Marengoni A, Vetrano DL, Onder G. Target population for clinical trials on multimorbidity: Is disease count enough? J Am Med Dir Assoc 2019;20:113-114.

6. Smith SM, Wallace E, O'Dowd T, Fortin M. Interventions for improving outcomes 


\section{THE JOURNAL OF NUTRITION, HEALTH \& AGING}

in patients with multimorbidity in primary care and community settings. Cochrane Database Syst Rev 2016;3:CD006560.

7. Salisbury C, Man MS, Bower P, et al. Management of multimorbidity using a patientcentred care model: A pragmatic cluster-randomised trial of the 3D approach. Lancet 2018;392;41e50.

8. Qato DM, Wilder J, Schumm LP, et al. Changes in prescription and over-thecounter medication and dietary supplement use among older adults in the United States, 2005 vs 2011. JAMA Intern Med 2016;176:473-482. Doi:10.1001/ jamainternmed.2015.8581.

9. Saraf AA, Petersen AW, Simmons SF, et al. Medications associated with geriatric syndromes and their prevalence in older hospitalized adults discharged to skilled nursing facilities. J Hosp Med 2016;11(10):694-700. Doi:10.1002/jhm.2614.

10. Sirois C, Domingues NS, Laroche ML, et al. Polypharmacy definitions for multimorbid older adults need stronger foundations to guide research, clinical practice and public health. Pharmacy (Basel). 2019;7(3):126. Publ 2019, Aug 29. Doi:10.3390/pharmacy7030126.

11. Saum KU, Schottker B, Meid AD, et al. Is polypharmacy associated with frailty in older people? Results from the ESTHER Cohort Study. J Am Geriatr Soc 2017;65(2):e27-e32.

12. Hartikainen S, Lonnroos E, Louhivuori K. Medication as a risk factor for falls Critical systematic review. J Gerontol A Biol Sci Med Sci 2008;72(10):1172-1181.

13. Herr M, Robine JM, Pinot J, Arvieu JJ, Ankri J. Polypharmacy and frailty: Prevalance, relationship, and impact on mortality in a French sample of 22350 old people. Pharmacoepidemiol Drug Safety 2015;24(6):637-646.

14. Jyrkka J, Enlund H, Lavikainen P, Sulkava R, Hartikainen S. Association of polypharmacy with nutritional status, functional ability and cognitive capacity over a three-year period in an elderly population. Pharmacoepidemiol Drug Safety 2011;20(5):514-522.

15. Rosted E, Schultz M, Sanders S. Frailty and polypharmacy in elderly patients are associated with a high readmission risk. Dan Med J 2016;63(9). Pii:A5274.

16. Wallace E, Stuart E, Vaughan N, Bennett K, Fahey T, Smith SM. Risk prediction models to predict emergency hospital admission in community-dwelling adults: A systematic review. Med Care 2014;52(8):751-765.

17. Flaherty JH, Perry HM 3rd, Lynchard GS, Morley JE. Polypharmacy and hospitalization among older home care patients. J Gerontol A Biol Sci Med Sci 2000;55(10):M554-M559.

18. Moon JH, Huh JS, Won CW, Kim HJ. Is polypharmacy associated with cognitive frailty in the elderly? Results from the Korean frailty and aging cohort study. J Nutr Health Aging 2019;23(10):958-965.

19. Maki H, Wakabayashi H, Nakamichi M, Momosaki R. Impact of number of drug types of clinical outcome in patients with acute hip fracture. J Nutr Health Aging 2019;23:937-942.

20. Tinetti ME, Bogardus ST Jr, Agostini JV. Potential pitfalls of disease-specific guidelines for patients with multiple conditions. N Engl J Med 2004;351(27):28702874 .

21. Bradley MC, Motterlini N, Padmanabhan S, et al. Potentially inappropriate prescribing among older people in the United Kingdom. BMC Geriatr 2014;14:72.

22. Hilmer SN, Mager DE, Simonsick EM, et al. A drug burden index to define the functional burden of medications in older people. Arch Intern Med 2007;167(8):781787.

23. Gray SL, Anderson ML, Dublin S, et al. Cumulative use of strong anticholinergics and incident dementia: A prospective cohort study. JAMA Intern Med 2015;175:401407.

24. Richardson K, Bennett K, Kenny RA. Polypharmacy including falls risk-increasing medications and subsequent falls in community-dwelling middle-aged and older adults. Age Ageing. 2015;44(1):90-96.
25. Gnjidic D, Hilmer SN. Potential contribution of medications to frailty. J Am Geriatr Soc 2012;60(2):401.

26. Rolland Y, Morley JE. Frailty and polypharmacy. J Nutr Health Aging 2016;20:645646.

27. Aprahamian I, Li SM, Suemoto CK, et al. Feasibility and factor structure of the FRAIL Scale in older adults. J Am Med Dir Assoc 2017;18:367.e11-367.e18.

28. Yuki A, Otsuka r, Tange C, et al. Polypharmacy is associated with frailty in Japanese community-dwelling older adults. Geriatr Gerontol Int 2018;18:1497-1500.

29. Aprahamian I, Biella MM, Vano Arico de Almeida G, et al. Polypharmacy but not potential inappropriate prescription was associated with frailty in older adults from a middle-income country outpatient clinic. J Frailty Aging 2018;7:108-112.

30. Moon JH, Huh JS, Won CW, Kim HJ. Is polypharmacy associated with cognitive frailty in the elderly? Results from the Korean Frailty and Aging Cohort study. J Nutr Health Aging 2019;23(10);958-965.

31. Shmuel S, Lund JL, Alvarez C, et al. Polypharmacy and incident frailty in longitudinal community-based cohort study. J Am Geriatr Soc 2019;67:2482-2489.

32. Murphy C, Dyer AH, Lawlor B, Kennelly SP, for the NILVAD Study Group. Potentially inappropriate medication use in older adults with mild-moderate Alzheimer's disease: Prevalence and associations with adverse events. Age and Ageing 2020;49:580-587.

33. Morley JE. Mild cognitive impairment - a treatable condition. J Am Med Dir Assoc 2014; $15: 1 \mathrm{e}-5.2$

34. Liau SJ, Lalic S, Sluggett JK, et al; on behalf of the Optimizing Geriatric Pharmacotherapy through Pharmacoepidemiology Network (OPPEN). Medication management in frail older people: Consensus principles for clinical practice, research, and education. J Am Med Dir Assoc 2020;21:doi.org/10.1016/j.jamda.2020.05.004

35. Rochon PA, Stukel TA, Sykora K, et al. Atypical antipsychotics and parkinsonism. Arch Intern Med 2005;165:1882-1888.

36. Munson JC, Bynum JP, Bell JE, et al. Patterns of prescription drug use before and after fragility fractures. JAMA Intern Med 2016;174:1531-1538.

37. The 2019 American Geriatrics Society Beers Criteria ${ }^{\circledR}$ Update Expert Panel. American Geriatrics Society 2019 Updated AGS Beers Criteria ${ }^{\circledR}$ for potentially inappropriate medication use in older adults. J Am Geriatr Soc 2019;67:674-694.

38. Gallagher P, O'Mahony D. STOPP (Screening Tool of Older Persons' potentially inappropriate Prescriptions): Application to acutely ill elderly patients and comparison with Beers' criteria. Age Ageing 2008;37:673-679.

39. O'Connor MN, O'Sullivan D, Gallagher PF, et al. Prevention of Hospital-Acquired Adverse Drug Reactions in Older People using screening tool of older persons' prescriptions and screening tool to alert to right treatment criteria: A cluster randomized controlled trial. J Am Geriatr Soc 2016;64:1558-1566.

40. Kuhn-Thiel AM, Wei $\beta$ C, Wehling M; FORTA authors/expert panel members Consensus validation of the FORTA (Fit fOR The Aged) List: A clinical tool for increasing the appropriateness of pharmacotherapy in the elderly. Drugs Aging 2014;31:131-140.

41. Hilmer SN, Mager DE, Simonsick EM, et al. A drug burden index to define the functional burden of medications in older people. Arch Intern Med 2007;167.8.781.

42. Sino CG, Sietzema M, Egberts TC, Schuurmans MJ. Medication management capacity in relation to cognition and self-management skills in older people on polypharmacy. J Nutr Health Aging 2014;18;44-49.

43. Stevenson JM, Davies JG, Martin FC. Medication-related harm: A geriatric syndrome. Age Ageing 2019;49:7-11. 